\title{
Defining linguistic reasoning
}

\section{Transposing and grounding a model for historical reasoning to the linguistic domain}

\author{
Roy Dielemans and Peter-Arno Coppen \\ Radboud Universiteit Nijmegen
}

Until recently, throughout the world, linguistic theory was virtually absent in secondary education, mostly limited to grammar teaching still based on 19th century linguistic theory. There is a growing call, however, for enriching grammar teaching with modern linguistic insights, integrating higher order critical thinking skills, like reasoning. This study tries to lay the groundwork for a model of linguistic reasoning in particular.

Based on a well-established model for historical reasoning (Van Boxtel \& Van Drie, 2018), a linguistic model is developed in two steps. First, the components of the historical model are theoretically analysed and transposed to the linguistic domain, and second, the model is applied in qualitative analysis of linguistic experts' reasoning.

It is found that the model fits linguistic reasoning fairy well: all central components can be observed, and are evenly distributed over different experts. It is concluded that the linguistic reasoning model can be used in the development of a new grammar pedagogy.

Keywords: subject-specific versus general critical thinking, historical reasoning, linguistic reasoning, L1 grammar teaching, linguistic repertoire

\section{Introduction}

In recent years, there has been a growing attention to enrich traditional grammar teaching with modern insights from linguistic theory. A clear example is the Australian curriculum, which has been rebuilt based on Hallidayan Systemic Functional Linguistics (see for instance Derewianka, 2018), but in other parts of the world as well a growing attention for research on the role of linguistic knowledge in the school curriculum is clearly visible (Coppen, 2010; Fontich \& Camps, 2013; Van Rijt, De Swart, \& Coppen, 2018; Myhill, 2018). So the focus seems to 
have turned to the enrichment of current pedagogical means to teach grammar, after many years of discussion which mainly questioned the necessity for teaching grammar or linguistics as a school subject altogether (the "grammar wars", cf. Locke, 2010). The challenge for this new focus lies for a large part in the fact that there has grown a big gap between current linguistic developments and traditional grammar education (Van Rijt, De Swart, \& Coppen, 2018; Van Rijt \& Coppen, 2017; Hudson \& Walmsley, 2005). Traditional grammar teaching all over the world is still mostly based on pre-structuralistic 19th century grammar theory (for Dutch, Den Hertog, 1892). Most linguistic theoretical insights since then have failed to enter into the school curriculum (Zwart, 2010).

Although teachers, parents and students often consider grammar education an extremely useful and relevant part of the language curriculum (Gartland \& Smolkin, 2015), traditional grammar teaching has been criticized all around the world for being too superficial, mainly based on decontextualized parsing exercises and rules of thumb. In terms of educational goals (Anderson \& Krathwohl, 2001), grammar education often does not go beyond applying superficial context rules to identify sentence parts, without attention to higher order concepts (Van Rijt, De Swart, \& Coppen, 2018) or higher order reasoning skills (Van Rijt, Wijnands, \& Coppen, 2019). Pedagogically, grammar education often is limited to drill-and-practice assignments with the help of mnemonic devices (Bonset \& Hoogeveen, 2010).

In this study, we will focus on linguistic reasoning, first because it can be considered as one of the key components of higher order thinking, and second, because it is already well-researched in a similar domain (historical reasoning). To answer the main research question What is linguistic reasoning?, we try to transpose the components of a well-established model for another discipline from the humanities, historical reasoning (Van Drie \& Van Boxtel, 2007; Van Boxtel \& Van Drie, 2018) into the linguistic domain based on a theoretical analysis grounded in our own observation of linguistic discussions in the literature and examples of linguistic reasoning elicited from experts. Next, we will qualitatively analyse linguistic experts' reasoning more systematically to see to what extent the model describes linguistic reasoning. So, more specifically, our research question will be broken down into the following sub questions:

1. How can a well-established model for historical reasoning be transposed to the linguistic domain?

2. To what extent can such a model be used to describe linguistic reasoning from experts? 


\subsection{Linguistic reasoning and critical thinking}

Traditional grammar teaching, as mentioned above, merely consists of decontextualized parsing exercises, focusing on only one correct answer (Van Gelderen, 2010). Parsing exercises (often based on rules of thumb) put emphasis on monoperspective convergent thinking, and do not stimulate critical thinking skills, let alone creative thinking. However, even simple sentence parsing can often be characterized as a 'messy problem' (Coppen, 2010), calling for higher order, critical thinking skills. For example, even for determining the subject in a sentence, it seems unwise, or even impossible, to rely on a single rule of thumb (like, for instance, person and number agreement). Linguistically, a subject is also characterized by meaning, case and word order properties. Not only does a full investigation of these properties add to a clearer picture of the subject at hand (a subject may agree with the verb, but be placed in a marked word order), in some cases agreement cannot be established (for instance, what is the subject of an imperative like Look out!, or a child's utterance as cookie nice?).

From a broader perspective, it can be observed that critical thinking has become a fundamental target within many disciplines, because it is thought to prepare students to deal with more and more complicated dilemmas in a globalized world (Renaud \& Murray, 2008).

In the past decades, there has been much debate on the definition of critical thinking (for an overview, cf. Moseley et al., 2005). In a seminal debate between Ennis (1989) and McPeck (1990), the difference and boundaries between generic and domain specific critical thinking skills have been disputed. Ennis argued that critical thinking should be considered as a general thinking activity, simply stating that critical thinking is the correct assessing of statements. He acknowledged that critical thinking skills may be applied variably to different domains, but maintained that they are general in nature. McPeck (1990) argued that thinking is always about something, so this would make critical thinking inherently domain specific. In an attempt to reconcile the two viewpoints, Moore (2004) proposed that critical thinking may be generic in theory, but in practice it must always be executed in a specific context. Therefore, domain specific properties of critical thinking are generally easy to transfer to other domains. Following Moore in considering that a model for critical thinking will always be a specification of some generic model, a manner to go about developing a specific model for linguistic reasoning would be to derive this model from other domains by changing specifications. 


\subsection{Historical reasoning}

A school subject domain which is in many respects comparable to linguistics is history teaching. In history, many problems are ill-structured and messy, just like the problems in linguistics. Answers can only be discussed by carefully evaluating a variety of properties of the situation. Moreover, the history domain can be considered a domain with a horizontal knowledge structure (Bernstein, 1999). Historical metaconcepts (like change, cause, context) have to be applied to historical phenomena, reasoning from multiple perspectives. For example, the word 'democracy' was introduced in the polis (city-state) of Athens in the sixth century $\mathrm{BC}$ where women were not allowed to vote, and slavery was common. Nowadays, students have other associations with the word 'democracy': women's voting is an integral part of democracy, whereas slavery is not. To reason about democracy in history, students need to contextualize this concept. This is no different from linguistics, where a concept like grammatical, for example, can be seen from different perspectives (acceptable within a specific society in a particular time frame, or defined by some linguistic descriptive or prescriptive grammar). In linguistics as well, metaconcepts like language change, language variation, social context have to be contextualized to linguistic phenomena.

In recent decades, history teaching has undergone a major shift in focus from knowing historical facts to reasoning with historical facts (McCarthy Young \& Leinhardt, 1998). In this context, a framework for historical reasoning has been developed by Van Drie and Van Boxtel (2007, 2018).

The framework for historical reasoning (cf. Figure 1) consists of a central core defining what historical reasoning can be about, surrounded by six main components describing what historical reasoning may consist of: asking historical questions, using historical sources, historical contextualization, providing (counter)arguments, using historical concepts and using meta-historical concepts. This basic model is embedded in a context of individual resources (historical knowledge, knowledge of historical metaconcepts and strategies, epistemological beliefs, interest in history), which in turn is embedded in a sociocultural context (public history, disciplinary history).

The model is used in history teaching to develop pedagogical arrangements to stimulate various components of historical reasoning, but also to analyse the reasoning skills of students, and to describe specific cases of historical reasoning.

Van Boxtel and Van Drie (2018) implicitly adhere to Moore's (2004) viewpoint that domain specific critical thinking skills are basically generic skills applied to a domain specific context by asserting: 'Reasoning is a subcategory of the broader concept of higher-order thinking, which comprises mental activities such as conceptualizing, evaluating and decision making' (Van Boxtel \& Van Drie, 2018, p. 150). 


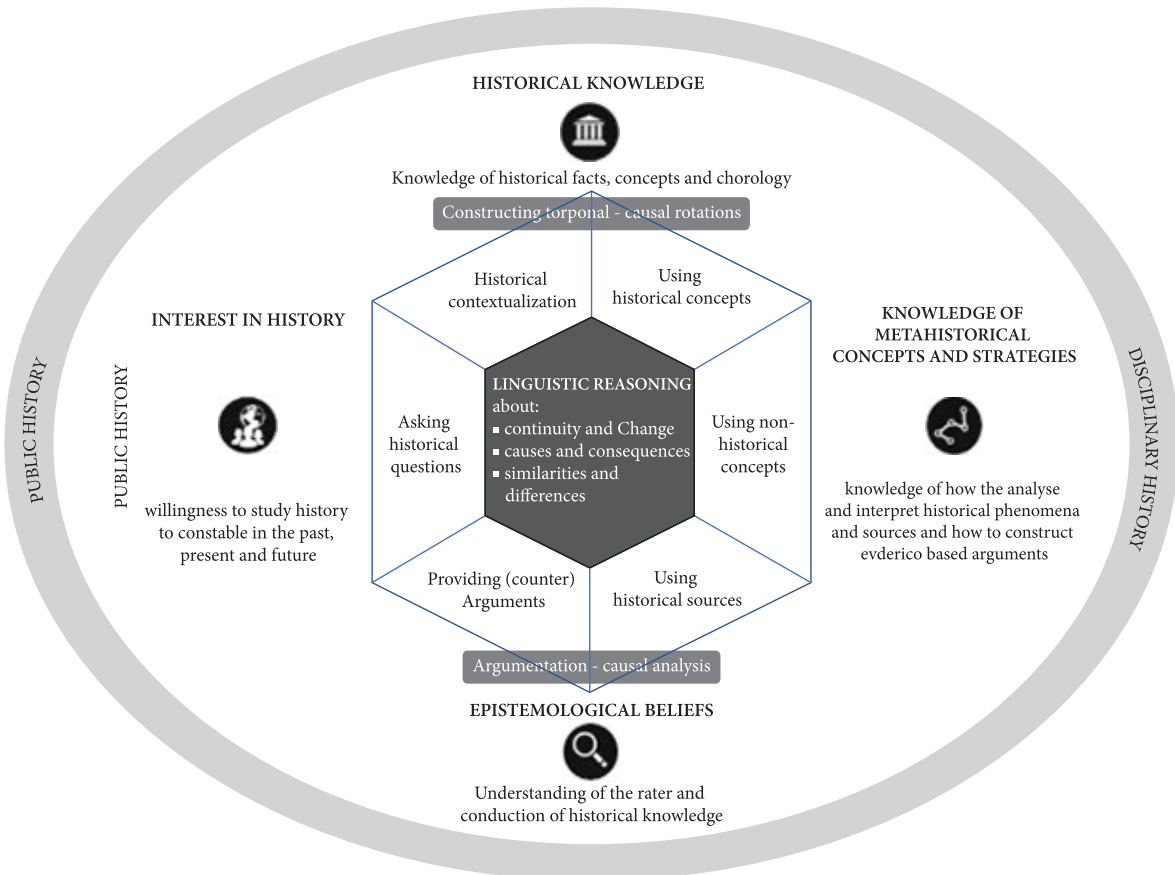

Figure 1. Types and components of historical reasoning and individual and sociocultural resources for historical reasoning. From Historical Reasoning: Conceptualizations and Educational Applications in The Wiley International Handbook of History Teaching and Learning (p152) by C. van Boxtel and J. van Drie, 2018, New York: Wiley-Blackwall. Copyright 2018, John Wiley \& Sons, Inc

This model for historical reasoning has been around for many years, and it seems to be well-established in the community of historical reasoning research. Therefore, it is a promising basis for developing a similar model for linguistic reasoning. This is the line we will be pursuing in the course of this paper.

\section{Method}

To transfer Van Drie and Van Boxtel's model for historical reasoning to the linguistic domain, we will apply the following methodology. First, we will theoretically analyse several components of the model and derive a linguistic counterpart as a preliminary result from this analysis. In doing this, we will draw from our expertise and our own observations of linguistic reasoning, both from linguistic literature and example reasonings. Subsequently, we will apply the components of our 
preliminary model to a more thorough qualitative analysis of linguistic reasoning in practice.

To create a data source for the analysis of linguistic reasoning, seven linguistic experts were selected using the following criteria: (a) the participants were full professors of Dutch linguistics at Dutch universities or (b) Ph.D. authors of significant Dutch linguistic work. These experts were confronted with three problems from the domain of the syntax-semantics interface, since this is the linguistic domain that is most closely related to what is taught school practice. We constructed three Dutch sentences that were undescribed (or only scarcely described) in linguistic theory (cf. Appendix A). This way, we ensured that the experts could not rely on their previous knowledge of some analysis. The fact that none of the experts in none of the problems referred to earlier analyses confirmed that the constructions were well-chosen. The experts were just asked to think aloud about the analysis of these problems, without any time restriction or feedback from the interviewer. They were not allowed to consult the literature, or to discuss their analysis with the interviewer. All thinking aloud protocols were transcribed (21 cases with in total 13.670 words, ranging from 973 to 3315 words per expert discussing 3 cases), and entered in Atlas-TI for further analysis. A grounded approach with open coding was used for qualitative analysis. Both authors coded parts of samples independently, and discussing differences they arrived at a consensus coding. Finally, the codes were grouped using the model components as sensitizing concepts.

The data source is used in both parts of the research: in the theoretical transposition of the historical model to the linguistic domain, examples from the source are taken to illustrate the transposition, and in the empirical exploration, the focus is not so much on proving that the components can be observed in the data (this was already established in the first part) but rather on the extent to which the model covers the data. In this exercise, an open coding is qualitatively and quantitatively related to the model components to investigate the relative importance of the components in linguistic reasoning (are all components equally observable in all experts' reasoning?), and to discover whether there are codes that are not covered by the model.

\section{Transposing the historical model to a linguistic model}

In this paragraph, we will theoretically transpose the model for historic reasoning to the linguistic domain. We will distinguish components, types and resources. 


\subsection{Components}

In this section, we will describe the theoretical transfer of all components of the model for historical reasoning. For each component, we will first briefly summarize the historical reasoning component, and subsequently propose a transfer to linguistic reasoning, tentatively grounding it in the data. Next, we will analyse the types, individual resources and social resources, and discuss how the linguistic model should be further adapted on empirical grounds.

\subsubsection{Asking historical questions}

Van Boxtel and Van Drie (2018) identify reasoning as a subcategory of the broader concept of higher-order thinking. They concentrate on 'historical reasoning' as a method to solve domain specific (historical) ill-structured problems. Asking historical questions is the 'engine' to start historical reasoning about historical phenomena and sources (Van Drie \& Van Boxtel, 2007). Asking questions may also be an important factor to guide students' reasoning. In history, four general types of questions are distinguished: descriptive, causal, comparative and evaluative. Students have to acquire skills to ask these types of questions to construct justifiable conclusions in relation to historical phenomena and sources, using prior knowledge and all available information. Moreover, students have to be aware of the context of the question (Van Drie \& Van Boxtel, 2007).

\section{Transfer to linguistic reasoning}

Just as history students have to learn the skills to ask historical questions, linguistic students would have to master skills to ask linguistic questions. But what are these linguistic questions? From our own linguistic experience, and the inspection of the experts thinking aloud protocols, we arrive at the following typology of linguistic questions:

1. Descriptive form and meaning questions, regarding the structural relations and categories of words, sentence parts or other linguistic units, or regarding the meaning of words, sentences or other linguistic units, often in relation to context factors or in comparison with other forms and meanings;

2. Evaluative questions, regarding personal or collective intuitions on acceptability, suitability, meaning or effect;

3. Prescriptive questions, regarding the language norm.

It may be remarked that prescriptive questions can be considered as some form of evaluative questions, but in our experience prescriptive questions are often limited to an application of some superficial prescriptive rule, without any introspective reflection or assessment of language reality (which is also typical for grammar 
teaching in a traditional school context). On the other hand, we chose not to distinguish comparative questions as a separate category, because in comparing different language forms or meanings, linguists always evaluate these (which makes the question inherently evaluative), and moreover, we consider comparison as a part of the linguistic repertoire (cf. 3.3, individual resources).

In the course of their analysis, the experts constantly asked themselves evaluative questions: they came up with variations on the case at hand, speak these aloud, and judged their grammaticality, acceptability ('That it comes as a surprise probably is not a very good sentence, Expert IV) or meaning aspects ('So this is really a strange construction. Actually from an external perspective you would say 'het ziet er naar uit dat', so you could say that you see it.' Expert II).

Perhaps unsurprisingly, linguistic experts hardly ever asked prescriptive questions: they rather stick to linguistic facts (like corpus data) or intuitions (their own, or reported) on acceptability. However, in a school context, linguistic questions are predominantly (if not exclusively) prescriptive ('is this a correct sentence?'). In all cases, the prescriptive question is undoubtedly a linguistic question, so although we have not encountered it in our data it has to be included here.

\subsubsection{Using historical sources}

Historians use historical sources to verify and select evidence for the interpretation of historical questions (Van Boxtel \& Van Drie, 2018). First of all, it is important to evaluate the reliability of historical sources. Secondly, we need historical sources in order to discuss a historical question or to provide evidence for claims about the past (Van Drie \& Van Boxtel, 2007). In history, primary sources from the time of the historical event itself are distinguished form secondary sources, which were created later to report about the historical event. When using historical sources we need to deal with two difficulties: historical sources are often incomplete and they are written in another era so that the specific Zeitgeist of that period has to be taken into account.

\section{Transfer to linguistic reasoning}

Linguistic experts use several linguistic sources to search arguments to construct answers to linguistic questions. They may refer to primary sources (examples of linguistic utterances or their own intuitions), or secondary sources (publications about language). Within the primary sources, we can distinguish objective sources (examples from real language use, like corpus data) and subjective sources (intuitions about language use). ${ }^{1}$ Secondary sources can be descriptive (grammars,

1. We are aware that there are methods to objectify language intuitions (e.g. Featherston, 2008), but the point is that the source is directly elicited from human subjects unlike, for example, a corpus, which can be collected without human interference. 
scholarly publications) or prescriptive (language advices, dictionaries, most school books).

In grammar education, students and teachers are often primarily concerned with prescriptive language norms in their argumentation.

Experts try to answer linguistic questions by evaluating the form and meaning of a linguistic unit, using language reality, in linguistic publications often in the form of text corpora. Experts also use their intuition (or reported intuitions from other language users). The latter is most often the case in the thinking aloud protocols, where experts do not have other sources at hand.

\subsubsection{Using historical concepts and using historical meta-concepts}

Discipline-bound concepts play an important role in education. Van Drie and Van Boxtel (2007) argue that students' understanding and use of historical concepts is one of the major goals of history education. They make a distinction between substantive and meta-historical concepts. Using historical concepts refers to substantive concepts to describe historical persons, events, phenomena, et cetera. A well-known example of a substantive concept is the concept Renaissance. On the one hand, it is a specific term for an era, but on the other hand it is a collective term for a variety of developments. Besides this inclusive substantive concepts, historians also distinguish unique substantive concepts, like $D$-day. D-day refers to a unique historical event, the Normandy landings of the allied forces on 6 June 1944 during the Second World War.

Van Boxtel and Van Drie (2018) relate historical meta-concepts to the methods of historians to describe historical processes and periods. Historical metaconcepts are more general concepts like change, continuity and cause-effect relationships. Meta-concepts are tools to describe an analysis of a context.

\section{Transfer to linguistic reasoning}

There are a number of similarities between historical and linguistic concepts. On a meta-conceptual level, a historical concept like change also seems relevant for the linguistic domain (language also changes), but linguistically, change is closely related to the metaconcept variation (as a result of change, language varies over time and place). This gives rise to a linguistic metaconcept variation and change. Another important metaconcept in the linguistic domain is the role of context in language use. The meaning of language forms is dependent on the individual characteristics of the language users involved, the socio-cultural characteristics of the situation, and the historical period of the language event. However, the principal metaconcept in linguistics is the relation between form and meaning. Language consists of a form which can have a specific meaning within a specific 
context. So metaconceptually, linguistic reasoning is about form and meaning, language in context and variation and change.

In a recent study investigating linguistic concepts, Van Rijt and Coppen (2017) identified and ranked twenty-six linguistic concepts which emerged from a Delphi study with linguistic experts. They divided them into three linguistic groups:

1. Structural concepts (syntactic functions, main syntactic categories)

2. Semantic concepts (negation, modality, tense, et cetera)

3. Relational concepts (word order, predication, complementation, et cetera)

Structural concepts relate to word or sentence structure. Semantic concepts focus on the semantics of sentences. Relational concepts link linguistic elements together (Van Rijt \& Coppen, 2017).

Compared to the historical concepts, Van Rijt and Coppen's classification seems to be a classification of inclusive substantive concepts, since they generalize over specific phenomena. The more traditional concepts, like word categories and sentence part functions (e.g. noun or subject, but also modern linguistic terminology for unique phenomena, such as small clause or modal particle), can be considered as unique substantive concepts.

It must be remarked that the study of Van Rijt and Coppen (2017) was restricted to concepts from the syntax-semantic interface. This means that they all relate to form and meaning, and less to language in context and variation and change. Concepts from these domains would probably include unique substantive concepts like discourse referent or Grimm's law and inclusive substantive concepts like specificity or vowel shift. However, no inventory of these concepts yet exists.

In the thinking-aloud protocols, experts very often referred to unique substantive concepts from the syntax domain (like subject and adjunct, and terms like small clause and subject raising), which are often related to inclusive structural concepts (like main syntactic categories) or inclusive relational concepts (complementation, predication), or even inclusive semantic concepts (like negation). On a metaconceptual level, they were reasoning about form and meaning mainly, and variation.

\subsubsection{Providing (counter)arguments}

Historical reasoning is more than just giving an opinion or selecting historical sources as evidence. A (historical) context includes multiple perspectives. Van Drie and Van Boxtel (2007, p. 99) state: 'to conclude, as a component of historical reasoning, argumentation concerns putting forward a claim about the past and supporting it with sound arguments and evidence through weighing different possible interpretations and taking into account counterarguments.' Taken 
together, a conclusion needs arguments and arguments need evidence. Providing (counter)arguments is inherent to reasoning.

\section{Transfer to linguistic reasoning}

Linguistic reasoning is of course also more than just giving an opinion or selecting linguistic sources as evidence. Just like historians, linguists support their claims with (linguistically) sound arguments, weighing different possibilities and taking counterarguments into account. The difference can only be in the nature of the arguments (sometimes linguistic arguments are motivated from a specific linguistic theory or model).

In the thinking-aloud protocols, the linguistic experts were constantly arguing, of course mostly with themselves since they were thinking aloud, about some linguistic analysis. Some experts immediately have a clear idea about such an analysis, and restrict themselves to providing just positive arguments in favour of this view. Others are searching, in a form of internal exploratory talk, for the best analysis, and in doing so they also consider counterarguments after having explored several possible analyses.

\subsubsection{Historical contextualization}

Wineburg (1998) refers to the Latin contextere, which means to 'weave together', creating a connection with time, place and other historical facts to build a historical context. In the framework of historical reasoning, contextualization is defined as 'situating a historical phenomenon, an object, statement, text, or picture in a temporal, spatial and social context in order to describe, explain, compare or evaluate it.'

\section{Transfer to linguistic reasoning}

The experts explore the linguistic context by asking themselves linguistic questions about the form and meaning of the sentence of the case. They try to imagine situations where the form at hand can be used, and what its meaning in that context would be ('so these are as it were stylistic variants, you can think of many situations where you can say both', Expert I). In linguistic research, specific sentences are often researched in text corpora, where their occurrences can be linked to several contextual metadata (sociographic background or subcultures, use in specific genres, etc.). For some linguistic fields of expertise (conversation analysis, pragmatics) this contextualization is even a raison d'etre. In general, linguistic contextualization can be defined as situating a linguistic phenomenon, sentence or word group in a specific (discourse) context, or linking it to contextual factors. 


\subsection{Types of reasoning}

In the model for historical reasoning, three types of historical reasoning are distinguished, based on what the reasoning is about. More specifically, historical metaconcepts are combined into three different types of reasoning, depending on whether it is about continuity and change, causes and consequences, or similarities and differences.

Following the analysis of linguistic metaconcepts above, this can be easily transposed to linguistic reasoning about form and meaning, language in context and variation and change.

Due to the task, all experts' reasoning in the thinking aloud protocols was about form and meaning. However, in a way, every linguistic discussion will be about form and meaning (just like, as Van Drie and Van Boxtel observe, historians will always be concerned with continuity and change). This is a central topic in linguistic theory. Besides that, reasoning can focus on language in a specific context of use, or the various patterns observed over a geographic, sociocultural or historical space.

\subsection{Individual resources}

Van Drie and Van Boxtel's model of reasoning is primarily embedded in the individual resources that historians make use of. They distinguish cognitive resources (knowledge of historical facts, concepts and chronology and knowledge of historical metaconcepts and strategies) and more reflective resources (interest in history, epistemological beliefs).

Just as historic experts use their knowledge of historical facts, concepts and chronology, linguistic experts use their knowledge of linguistic constructions (like passive, or idiosyncrasies of the comparison construction), concepts and metaconcepts in their reasoning. More specifically, the experts in our think aloud protocols often rely on entire theoretical frameworks (cognitive linguistics, generative linguistics, traditional grammar), giving rise to specific concepts like small clause or subject raising.

Linguistic experts, by their knowledge of linguistic variation and history, have also developed a more than fine-grained awareness of linguistic principles, by which they are able to recognize well-known linguistic properties or patterns in everyday language. They have mastered a large linguistic repertoire of methods enabling them to investigate language form and meaning linguistically. Epistemically, linguists do not derive knowledge from superficial observation or authority only, but they typically come to a deeper understanding by context-dependent reasoning. Linguists, by nature of their profession, are also interested in language, 
and motivated to investigate. There are several similarities between historical and linguistic reasoning in relation to the individual resources. As already mentioned, this study identified a lot of similarities by transposing the model of historical reasoning into a model for linguistic reasoning. This implies that the required individual resources also largely match. Linguistic knowledge, linguistic skills, language awareness and attitude are individual resources that influence the linguistic reasoning skills.

\subsection{Sociocultural resources}

Van Boxtel and Van Drie (2018) note that historical reasoning takes place in the context of both disciplinary history (historic sciences) and public history/collective memory. Likewise, linguistic reasoning always takes place in the context of disciplinary linguistics or folk linguistics/popular language beliefs.

Linguistic reasoning taking place within some linguistic theory usually draws heavily from some common body of knowledge, which also may vary in time. For example, around the 1980s, linguistic reasoning within Chomskyan generative grammar was all about relating movement to anaphoric reference and the locality restrictions involved, but in the 1990s reasoning revolved around economic principles of sentence derivation by some merge-operation. Reasoning within a popular language belief context is often about superficial language rules, and argumentation is based on some authority (like spelling rules) or popular logic (like why it is illogical to say that you are 'literally dying to see this'). The experts in our think aloud protocol indeed occasionally refer to such current theoretical concepts.

\subsection{Summary}

Summarizing, the various components of the model for historical reasoning can be transposed to the linguistic domain as in Table 1.

\section{Applying the model to linguistic reasoning}

The second research question is the question to what extent can such a model be used to describe linguistic reasoning form experts. To apply the model for linguistic reasoning to the analysis of linguistic experts' data, we coded the thinking aloud protocols in an open coding approach, concentrating on what the experts were actually doing in their reasoning. For instance, if the expert classified a sentence part with the linguistic term subject, we coded this both as Classifying 
Table 1. Overview of the components, types, individual and sociocultural resources of historical and linguistic reasoning

\begin{tabular}{|c|c|c|}
\hline & Historical reasoning & Linguistic reasoning \\
\hline Component & $\begin{array}{ll}\text { 1. } & \text { Asking historical questions } \\
\text { 2. } & \text { Providing (counter) } \\
\text { arguments } \\
\text { 3. Historical contextualization } \\
\text { 4. Using historical sources } \\
\text { 5. Using historical concepts } \\
\text { 6. Using meta-historical } \\
\text { concepts }\end{array}$ & $\begin{array}{ll}\text { 1. } & \text { Asking linguistic questions } \\
\text { 2. } & \text { Linguistic argumentation } \\
\text { 3. } & \text { Linguistic contextualization } \\
\text { 4. } & \text { Using linguistic sources } \\
\text { 5. } & \text { Using Linguistic concepts } \\
\text { 6. } & \text { Using Linguistic repertoire }\end{array}$ \\
\hline Types & $\begin{array}{l}\text { - Continuity and change } \\
\text { - Causes and consequences } \\
\text { - Similarities and differences }\end{array}$ & $\begin{array}{l}\text { - Form and meaning } \\
\text { - Language in context } \\
\text { - Variation and change }\end{array}$ \\
\hline $\begin{array}{l}\text { Individual } \\
\text { resources }\end{array}$ & $\begin{array}{l}\text { - Knowledge of historical facts, } \\
\text { concepts and chronology } \\
\text { - Knowledge of historical } \\
\text { metaconcepts and strategies } \\
\text { - Epistemological beliefs } \\
\text { - Interest in history } \\
\text { - Linguistic knowledge }\end{array}$ & $\begin{array}{l}\text { - Linguistic skills (critical thinking, } \\
\text { strategies an multiple perspectives) } \\
\text { - Language awareness (epistemological } \\
\text { beliefs) } \\
\text { - Attitude (interest, motivation and } \\
\text { reflection) }\end{array}$ \\
\hline $\begin{array}{l}\text { Sociocultural } \\
\text { resources }\end{array}$ & $\begin{array}{l}\text { - Disciplinary history (historic } \\
\text { sciences) } \\
\text { - Public history/collective } \\
\text { memory }\end{array}$ & $\begin{array}{l}\text { - Disciplinary linguistics } \\
\text { - Folk linguistics/popular language beliefs }\end{array}$ \\
\hline
\end{tabular}

and Using linguistic concepts. If the expert for example used a standardized test in Dutch grammar like the eenzinsdeelproef (one-sentence-part-test), in which a constituent is topicalized, we coded it as both Using standardized linguistic tests and Transforming. An open consensus coding was reached in 19 codes, which were grouped with the Linguistic reasoning model components from Table 2 as sensitizing group codes. Results are given in Table 2.

We found that codes cover all six central components of the model, as well as the Types of reasoning (especially in a focus on form or meaning), and the individual resource Attitude. Other individual resources from the model are in fact often implicit in what the experts actually do: when they use linguistic concepts, it is implied that they have some knowledge of these concepts (or else they would not be able to use them). The same holds for linguistic skills: using a linguistic repertoire presupposes some mastering of linguistic skills. Likewise, using specific theory-related terminology indicates the existence of disciplinary linguistic 
Table 2. Model components, codes and quotations

\section{Model}

component

Code

Example quotation (translated in English)

1. Asking

linguistic

questions

2. Linguistic

argumentation

\section{Linguistic}

contextualization

Comparing

Linguistic

inferring

Providing arguments

Drawing
conclusions

Asking

Classifying

'What kind of word groups are these?' (Expert IV, asking

aloud a linguistic question)

'But, it is at the same time also a kind of idiom.' (Expert I, classifying a phrase)

'We see here this impersonal it again, which you also find in it rains, which shows that a subject is needed' (Expert VII, drawing a conclusion about the properties of a sentence)

'Some would analyse this as a prepositional element. There are others who would analyse this as a kind of particle.' (Expert VII, referring to linguistic inference by others)

'That we have a predicate, you can see from the fact that it has to precede the verb in the subordinate clause, that Jan wet rains not that Jan rains wet.' (Expert IV, referring to the Dutch word order in subordinate clauses)

So actually, then this (points to the word 'Jan') is indeed a, er, grammatically seen, the subject, see, 'Jan ráíns wet' but 'the people ráín wet' (Expert II, comparing singular and plural variant of a sentence)

Repeating 'That comes as a surprise' (Expert III, reading aloud the aloud

4. Using

Referring to sentence to be analysed)

linguistic sources

language

reality

Probing

intuition

Referring to

'That kind of construction typically has no external argument, so no Agens, somebody who does it.' (Expert V, referring to typical use of a construction)

language 'whereas it is terribly common in Dutch' (Expert I, referring to frequency of use)

norm

$\begin{array}{ll}\text { 5. Using } & \text { Using } \\ \text { linguistic } & \text { linguistic } \\ \text { concepts } & \text { concepts }\end{array}$

That is a word order that is prescribed in written Dutch, but it is not in accordance with the intuitions of most speakers' (Expert V, referring to language prescription)

'Let's call it a small clause construction.' (Expert VI, introducing a linguistic concept) 
Table 2. (continued)

\begin{tabular}{|c|c|c|}
\hline $\begin{array}{l}\text { Model } \\
\text { component }\end{array}$ & Code & Example quotation (translated in English) \\
\hline \multirow{5}{*}{$\begin{array}{l}\text { 6. Using } \\
\text { linguistic } \\
\text { repertoire }\end{array}$} & Deleting & $\begin{array}{l}\text { 'It is an obligatory element, you cannot just delete it' } \\
\text { (Expert IV, considering deleting an element) }\end{array}$ \\
\hline & Inserting & $\begin{array}{l}\text { 'If you add another adverb That comes probably as a } \\
\text { surprise' (Expert IV, inserting the adverb 'probably' in the } \\
\text { target sentence) }\end{array}$ \\
\hline & Substituting & $\begin{array}{l}\text { 'The nice thing here is that the subordinate clause can't be } \\
\text { replaced by some NP, nominal phrase' (Expert IV, } \\
\text { considering replacing a subordinate clause by a noun } \\
\text { phrase) }\end{array}$ \\
\hline & Transforming & $\begin{array}{l}\text { 'The boys rain wet becomes plural and you could replace it } \\
\text { by a pronoun appearing in a nominative form' (Expert IV, } \\
\text { transforming a sentence by performing multiple } \\
\text { operations) }\end{array}$ \\
\hline & $\begin{array}{l}\text { Applying } \\
\text { standardized } \\
\text { linguistic } \\
\text { tests }\end{array}$ & $\begin{array}{l}\text { 'Because you have the eenzinsdeelproef, that works well' } \\
\text { (Expert IV, referring to a well-known Dutch test for } \\
\text { constituents, which consists of topicalizing a phrase which } \\
\text { causes inversion of the subject and the finite verb) }\end{array}$ \\
\hline Attitude & $\begin{array}{l}\text { Showing } \\
\text { interest }\end{array}$ & $\begin{array}{l}\text { 'Yes, that is also fun' (Expert II, someone enjoys the target } \\
\text { sentences) }\end{array}$ \\
\hline \multirow[t]{2}{*}{ Types } & $\begin{array}{l}\text { Focusing on } \\
\text { form }\end{array}$ & $\begin{array}{l}\text { 'I could not put that in any other word order' (Expert I, } \\
\text { focusing on word order rather than meaning aspects) }\end{array}$ \\
\hline & $\begin{array}{l}\text { Focusing on } \\
\text { meaning }\end{array}$ & $\begin{array}{l}\text { 'Look like, I think that's the meaning here' (Expert III, } \\
\text { focusing on meaning rather than form aspects) }\end{array}$ \\
\hline
\end{tabular}

theory. In short, it seems that the observable components of the model indeed emerge in a qualitative coding.

To further explore the relative importance of these code groups in the protocols of all experts together, we counted occurrences in the whole dataset (total results in Appendix B).

We see that Using linguistic concepts (331) and Linguistic argumentation (279) are by far the most frequent categories, showing that indeed the experts mostly use two important domain specific components of the model in their reasoning. With the exception of Attitude (which is less likely to occur in scientific reasoning), all components seem to be used by all experts.

To get a clearer picture of the relative importance of the categories per expert, we computed the number of times a category occurred per expert per 1000 words 


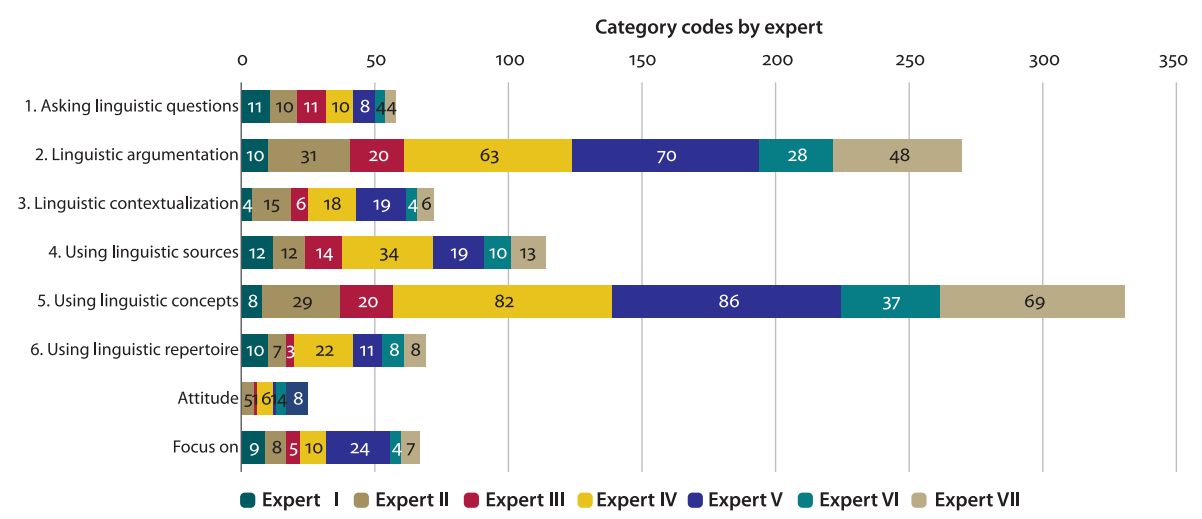

Figure 2. Category codes by experts

(since more words make all categories' occurrences more likely), and in order to compare experts we computed percentages of these numbers per expert. Results are in Figure 3.

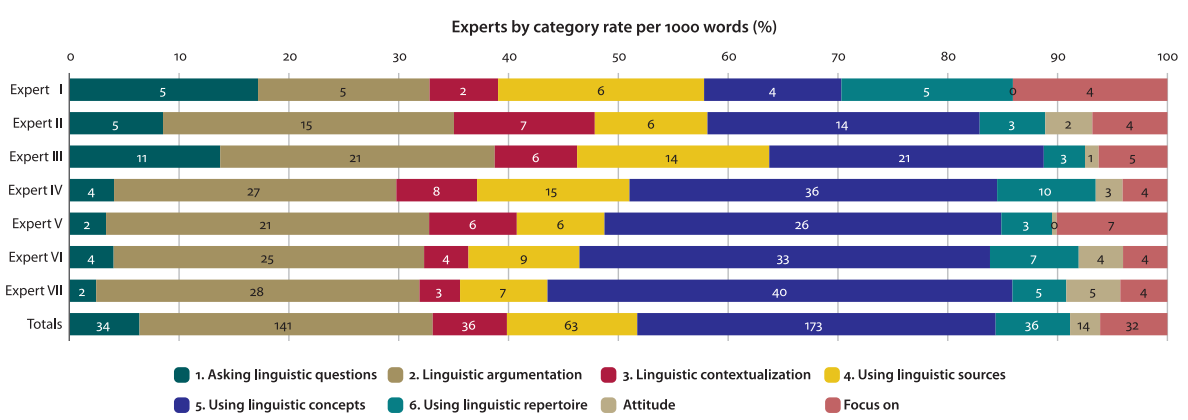

Figure 3. Experts by category rate per 1000 words

From this figure we can conclude that experts differ in their use of components, but most experts closely follow the general pattern (the percentages for Totals); Using linguistic concepts and Linguistic argumentations are the components all experts use most (with the exception of expert I), and with the exception of Attitude, no components are completely absent in any expert's reasoning. The difference in use seems to be related to the experts' background. Expert IV and V were specialists in Chomskyan linguistics, and they used a lot of theory-specific terminology and argumentation, whereas other experts tried to analyse the cases using more traditional, or even general categories.

Summarizing the results of the theoretical transposition of the model for historical reasoning into a linguistic model and the qualitative analyses of the 
experts' reasoning using this model, we arrive at the linguistic model depicted in Figure 4. This model corresponds to the model for historical reasoning, and the components in bold italic are indeed empirically grounded in linguistic experts' reasoning. The components that are not in bold italic are less observable in reasoning data, but either they can be argued to be observed implicitly, or they can be argued to be present on general grounds (like the fact that there exists a linguistic discipline or that there is something like folk linguistics).

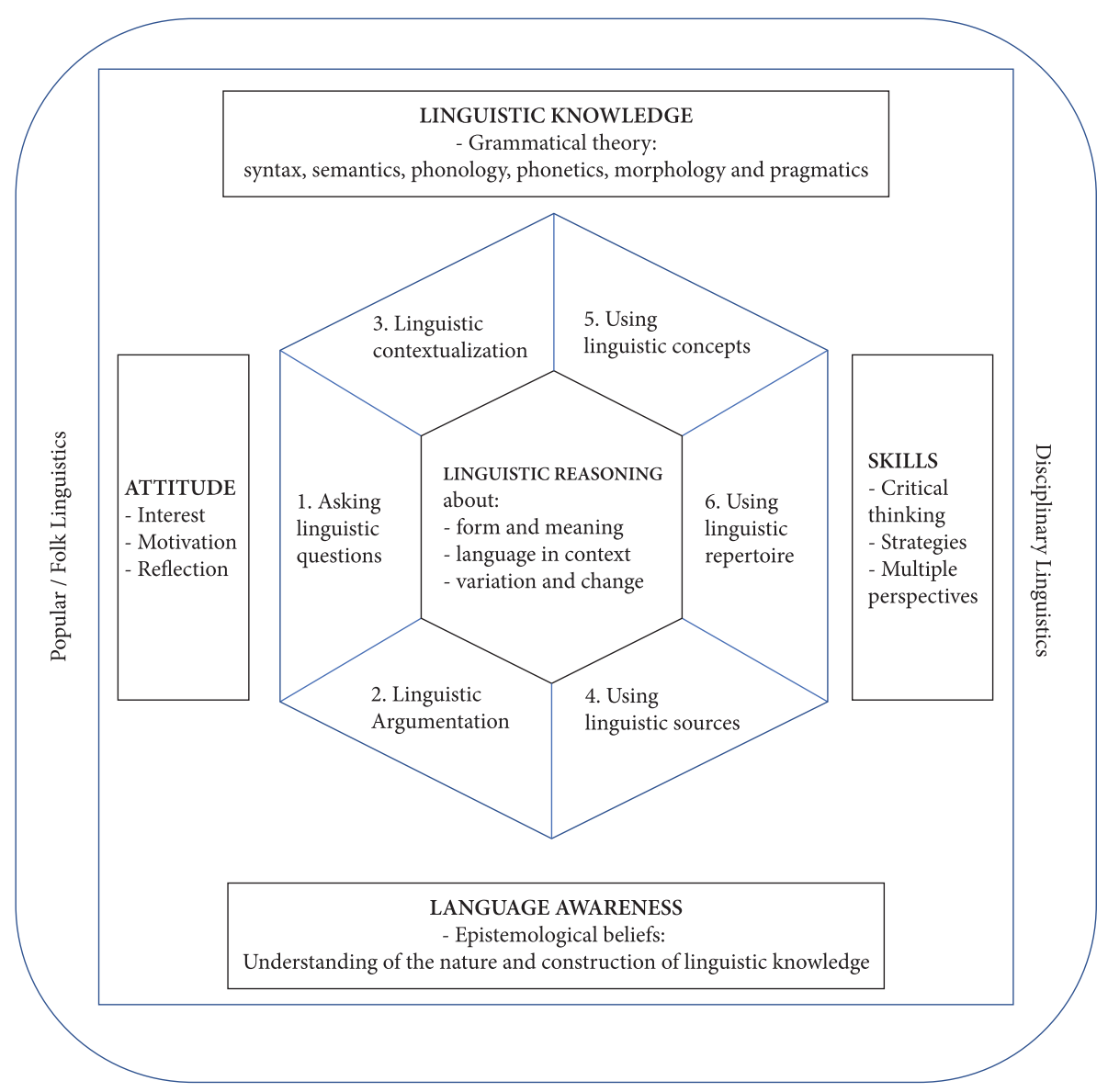

Figure 4. Framework for linguistic reasoning

In summary, the central core of the framework describes what linguistic reasoning can be about. In our data we found reasoning about form and meaning (which will always be relevant in linguistic reasoning), but in other tasks the other metaconcepts (like variation and change) are perfectly conceivable. In the design 
of the grammatical problems, there was a focus on syntactic-semantic issues. It depends on the task which form of reasoning is more observable.

The central core is surrounded by components specifying what linguistic reasoning actually consists of. Just like for historical reasoning, the central hexagon consists of six components, the leftmost three of which focus on the process of reasoning, whereas the rightmost three specify how several resources are used in reasoning.

The central core is embedded in four individual resources consisting of (collective) knowledge and beliefs (the vertical dimension) and (individual) attitude and skills (the horizontal dimension). Finally, the outer hexagon depicts the context of linguistic reasoning (disciplinary linguistics and popular/folk linguistics).

\section{Conclusions and discussion}

The two sub questions of our study were:

1. How can a well-established model for historical reasoning be transposed to the linguistic domain?

2. To what extent can such a model be used to describe linguistic reasoning from experts?

With respect to the first sub question, we may conclude that the model for historical reasoning by Van Boxtel and Van Drie (2018) can be transposed theoretically fairly easily to a model for linguistic reasoning. The resulting model (Figure 4) is congruent with the historical model. Although our qualitative analysis concentrated on the central components of reasoning, leaving individual resources and context for further research, the theoretical transposition of the outer components of the historical model to the linguistic domain seems straightforward.

The second sub question is answered by our qualitative analysis of actual linguistic experts' reasoning, We found that all central components of the model can indeed be observed in all examples of linguistic reasoning (not just in single examples), and that they occur for all experts in a similar way. Therefore, we may conclude that the model for linguistic reasoning is a good description instrument. Although the grammatical problems used as reasoning stimuli in this study (Appendix I) did not trigger the experts to reason very much about language in context and variation and change.

The main research question is What is linguistic reasoning? In line with our model, we can conclude that linguistic reasoning is a process that departs from a central question, and consists of activities (asking linguistic questions, linguistic argumentation and linguistic contextualization) for which different resources are 
used (linguistic concepts, linguistic sources and linguistic repertoire). This central core is influenced by personal, individual resources (knowledge \& beliefs, attitude $\&$ skills), and operates within the context of popular and disciplinary linguistics.

Of course the present study has some limitations. From a theoretical perspective, one of the most striking limitations is that the model concentrates on the components and resources of reasoning (what is reasoning?), and not on the way in which reasoning is performed (how is reasoning performed?). A model comprising the latter as well would probably have to contain components describing the strategy of reasoning (e.g. inductive, deductive, abductive), the phases of reasoning (e.g. the scientific cycle, or in any case exploring, conceptualizing, creating), and the path of reasoning (e.g. convergent, divergent, backtracking). Since the model by Van Boxtel and Van Drie was limited to the what (presumably because the way reasoning is applied is not considered a component of reasoning per se, but rather involves the use of reasoning), we chose for the same delimitation. However, in order to be able to implement the model in pedagogical design, the how should be taken into account, because it will make the reasoning process visible. This allow teachers to analyse and guide students linguistic reasoning.

Some of these how components of reasoning can actually be observed in the experts' reasoning data. We do see the experts alternate between inductive, deductive and even abductive strategies, and their reasoning proceeds in small cycles where they explore and conceptualize a line of reasoning, and integrate this into a creative part of a solution. Initially, experts tend to diverge, in order to explore the phenomenon at hand, but at various points they choose convergent paths towards (partial) solutions for the analysis. This aspect is more complex than a binary opposition, in that sometimes experts also return to previous points in their reasoning (backtracking). For instance, Expert II, in analysing the sentence It looks like my plan is being smashed into the ground (see Appendix A for the exact Dutch wording) first looks at the main clause, than dives into the subordinate clause, finally returning to the main clause to express that this is the interesting part of the analysis. So, more research is necessary to investigate how experts (and for that matter, students) apply the model components to arrive at linguistic reasoning.

Of course the empirical part of our research has some limitations too. Although 21 reasonings from 7 experts on 3 cases is a fair amount of data, the cases were limited in linguistic scope (they focused on the syntax-semantics interface), and the experts were also chosen within this scope. However, the empirical exercise was not so much to cover all of linguistics, but to explore if all central model components are significantly used in real life linguistic reasoning.

Concluding that the model we arrived at sufficiently describes the components of linguistic reasoning, the obvious next step would be to design and implement pedagogical arrangements for grammar teaching based on this model, and 
aiming at developing students' learning of linguistic reasoning by addressing the specific components. In Van Rijt, De Swart, Wijnands and Coppen (2019), the use of linguistic concepts is already investigated, and found to be an important factor for the quality of students' reasoning, as judged by linguistic experts. The current study offers some clear implications for such further research. More specifically, there are three ways in which the model can be applied. First, in order to develop pedagogical arrangements specific work forms might be chosen that focus on specific components of linguistic reasoning. Second, the model can be implemented in pedagogical arrangements in order to provide students with a tool for selfmonitoring their own reasonings, identifying components that deserve attention, and third, the model could be used to develop instruments for assessing reasoning by judging different components and providing more detailed feedback.

\section{Funding}

This project was supported by the Dudoc-Alfa scholarship, a program of Vakdidactiek Geesteswetenschappen, Trans 10, 3512 JK Utrecht, awarded to Roy Dielemans.

\section{References}

Anderson, L.W., Krathwohl, D. R., \& Bloom, B.S. (2001). A taxonomy for learning, teaching, and assessing: A revision of Bloom's taxonomy of educational objectives. Boston, MA: Allyn \& Bacon.

Bernstein, B. (1999). Vertical and horizontal discourse: An essay. British Journal of Sociology of Education, 20(2), 157-173. https://doi.org/10.1080/01425699995380

Bonset, H., \& Hoogeveen, M. (2010). Taalbeschouwing. Een inventarisatie van empirisch onderzoek in basis- en voortgezet onderwijs. [Language contemplation. An inventory of empirical research in primary and secondary education] Enschede: SLO.

Coppen, P.A. (2010). De taal is een rommeltje. [Language is a messy problem] In H. Hulshof, \& T. Hendrix, Taalkunde in het voortgezet onderwijs. Special Levende Talen Magazine. Amsterdam: Levende Talen, 26-29.

Den Hertog, C. H. (1892). Nederlandsche spraakkunst. Handleiding ten dienste van aanstaande (taal)onderwijzers. [Dutch grammar. Manual for the benefit of prospective (language) teachers] Amsterdam: 1e druk. De leer van den enkelvoudigen zin.

Derewianka, B. (2018). Changing approaches to the conceptualization and teaching of grammar. International Handbook of English Language Teaching, 843-858. https://doi.org/10.1007/978-0-387-46301-8_56

Ennis, R.H. (1989). Critical thinking and subject specificity: Clarification and needed research. Educational Researcher, 18(3), 4. https://doi.org/10.2307/1174885

Featherston, S. (2008). Thermometer judgements as linguistic evidence. In C. M. Riehl, \& A. Rothe (Eds.), Was ist linguististische Evidenz? (pp. 69-90). Aachen: Shaker Verlag. 
Fontich, X., \& Camps, A. (2013). Towards a rationale for research into grammar teaching in schools. Research Papers in Education, 29(5), 598-625. https://doi.org/10.1080/02671522.2013.813579

Gartland, L. B., \& Smolkin, L. B. (2015). The histories and mysteries of grammar instruction. The Reading Teacher, 69(4), 391-399. https://doi.org/10.1002/trtr.1408

Hudson, R., \& Walmsley, J. (2005). The English Patient: English grammar and teaching in the twentieth century. Journal of Linguistics, 41(3), 593-622. https://doi.org/10.1017/So022226705003464

Locke, T. (2010). Beyond the grammar wars: A resource for teachers and students on developing language knowledge in the English/literacy classroom. London, England: Routledge. https://doi.org/10.4324/9780203854358

McCarthy Young, K., \& Leinhardt, G. (1998). Wildflowers, sheep and democracy: The role of analogy in the teaching and learning of history. In J. F. Voss, \& M. Carretero, Learning and reasoning in history. International review of history education (vol. 2, pp. 154-156). London: Woburn.

McPeck, J.E. (1990). Critical thinking and subject specificity: A reply to Ennis. Educational Researcher, 19(4), 10-12. https://doi.org/10.2307/1176382

Moore, T. (2004). The critical thinking debate: How general are general thinking skills? Higher Education Research \& Development, 23(1), 3-18. https://doi.org/10.1080/0729436032000168469

Moseley, D., Baumfield, V., Elliot, J., Gregson, M., Higgins, S., Miller, J., \& Newton, D. (2005). Frameworks for thinking: A handbook for teaching and learning. Cambridge, England: Cambridge University Press. https://doi.org/10.1017/CBO9780511489914

Myhill, D. (2018). Grammar as a meaning-making resource for language development. Contribution to a special issue Working on Grammar at School in L1 Education: Empirical Research Across Linguistic Regions. L1-Educational Studies in Language and Literature, 18, 1-21. https://doi.org/10.17239/L1ESLL-2018.18.04.04

Renaud, R.D., \& Murray, H.G. (2008). A comparison of a subject-specific and a general measure of critical thinking. Thinking Skills and Creativity, 3(2), 85-93. https://doi.org/10.1016/j.tsc.2008.03.005

Van Boxtel, C., \& Van Drie, J. (2018). Historical reasoning. The Wiley International Handbook of History Teaching and Learning (pp. 149-176). https://doi.org/10.1002/9781119100812.ch6

Van Drie, J., \& Van Boxtel, C. (2007). Historical reasoning: Towards a framework for Analyzing students' reasoning about the past. Educational Psychology Review, 2o(2), 87-110. https://doi.org/10.1007/s10648-007-9056-1

Van Gelderen, A. (2010). Does explicit teaching of grammar help students to become better writers? Insights from empirical research. In T. Locke (Ed.), Beyond the grammar wars. A resource for teachers and students on developing language knowledge in the English/literacy classroom (pp. 109-128). New York: Routledge.

Van Rijt, J. \& Coppen, P.A. (2017). Bridging the gap between linguistic theory and L1 grammar education - experts' views on essential linguistic concepts. Language Awareness, 26(4), 360-38o. https://doi.org/10.1080/09658416.2017.1410552

Van Rijt, J., De Swart, P. \& Coppen, P.A. (2018). Linguistic concepts in L1 grammar education: A systematic literature review. Research Papers in Education. New York: Routledge.

Van Rijt, J., Wijnands, A. \& Coppen, P.A. (2019). Dutch teachers' beliefs on linguistic concepts and reflective judgement in grammar teaching. L-1 Educational Studies in Language and Literature, 19, 1-28. 
Van Rijt, J., De Swart, P., Wijnands, A. \& Coppen, P.A. (2019). When students tackle grammatical problems: Exploring linguistic reasoning with linguistic metaconcepts in L1 grammar education. Linguistics and Education, 52, 78-88. https://doi.org/10.1016/j.linged.2019.06.004

Wineburg, S. S. (1998). Reading Abraham Lincoln: An expert/expert study in the interpretation of historical texts. Cognitive Science, 22, 319-346. https://doi.org/10.1207/s155167096og2203_3

Zwart, J.W. (2010). Levende talen. In H. Hulshof, \& T. Hendrix, Taalkunde en het schoolvak Nederlands [Linguistics and the school subject Dutch] (pp. 51-54). Amsterdam: Levende Talen Magazine.

\section{Appendix A. Grammatical problems}

For the thinking aloud protocol, experts were confronted with the following question about three (Dutch) sentences. The sentences were given one by one. Experts had to complete their thoughts before a next sentence was provided.

Question Can you think aloud how this sentence is linguistically structured?

I. Dat komt als een verrassing.

('That comes as a surprise')

II. Jan regent nat.

(Lit: 'Jan rains wet.' John is raining wet)

III. Het ziet ernaar uit dat mijn plan de bodem wordt ingeslagen.

(Lit: 'It looks there+to out that my plan the ground is in+smashed.' It looks like my plan is being dashed)

Appendix B. Figure 3. Code table experts' reasoning: numbers per code group and percentage per expert, means and standard deviations 


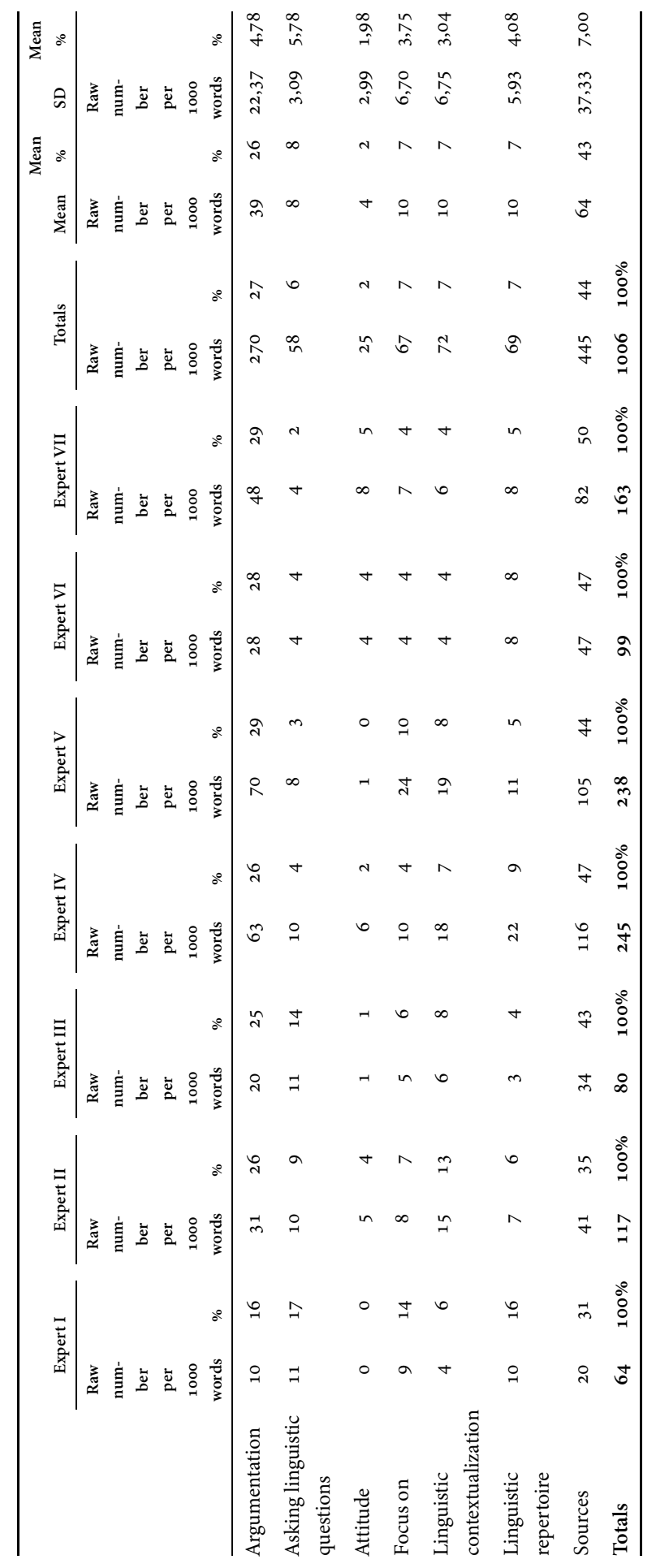




\section{Address for correspondence}

Roy Dielemans

Radboud Docenten Academie

Radboud University Nijmegen

Valleistraat 125

3902 ZB Veenendaal

Netherlands

r.dielemans@docentenacademie.ru.nl

(iD) https://orcid.org/oooo-0001-9138-0771

\section{Co-author information}

Peter-Arno Coppen

Faculteit Letteren

Radboud Docenten Academie

Radboud Universiteit Nijmegen

p.a.coppen@let.ru.nl

\section{Publication history}

Date received: 14 October 2019

Date accepted: 30 November 2020

Published online: 8 January 2021 